Reihe Ökonomie Economics Series

\title{
Inducing Human Capital Formation: Migration as a Substitute for Subsidies
}

Oded Stark, Yong Wang 
Reihe Ökonomie Economics Series

\section{Inducing Human Capital Formation: Migration as a Substitute for Subsidies}

Oded Stark, Yong Wang

April 2001

Institut für Höhere Studien (IHS), Wien Institute for Advanced Studies, Vienna 


\section{Contact:}

Oded Stark

Department of Economics

University of Oslo

P.O. Box 1095 Blindern

$\mathrm{N}-0317$ Oslo, NORWAY

푤: $+47 / 22 / 855112$

Fax: $+47 / 22 / 857946$

and

University of Vienna

Alser Straße 21/9

A-1080 Vienna, AUSTRIA

Yong Wang

Department of Economics

The Chinese University of Hong Kong

Shatin, N.T., Hong Kong

email: yongwang@cuhk.edu.hk

Founded in 1963 by two prominent Austrians living in exile - the sociologist Paul F. Lazarsfeld and the economist Oskar Morgenstern - with the financial support from the Ford Foundation, the Austrian Federal Ministry of Education and the City of Vienna, the Institute for Advanced Studies (IHS) is the first institution for postgraduate education and research in economics and the social sciences in Austria. The Economics Series presents research done at the Department of Economics and Finance and aims to share "work in progress" in a timely way before formal publication. As usual, authors bear full responsibility for the content of their contributions.

Das Institut für Höhere Studien (IHS) wurde im Jahr 1963 von zwei prominenten Exilösterreichern dem Soziologen Paul F. Lazarsfeld und dem Ökonomen Oskar Morgenstern - mit Hilfe der FordStiftung, des Österreichischen Bundesministeriums für Unterricht und der Stadt Wien gegründet und ist somit die erste nachuniversitäre Lehr- und Forschungsstätte für die Sozial- und Wirtschaftswissenschaften in Österreich. Die Reihe Ökonomie bietet Einblick in die Forschungsarbeit der Abteilung für Ökonomie und Finanzwirtschaft und verfolgt das Ziel, abteilungsinterne Diskussionsbeiträge einer breiteren fachinternen Öffentlichkeit zugänglich zu machen. Die inhaltliche Verantwortung für die veröffentlichten Beiträge liegt bei den Autoren und Autorinnen. 


\begin{abstract}
When productivity is fostered by an individual's own human capital as well as by the economy-wide average level of human capital, individuals under-invest in human capital. The provision of subsidies for the formation of human capital, conditional on the subsidy being self-financed by tax revenues, can bring the economy to its socially optimal level of human capital. Yet a strictly positive probability of migration to a richer country, by raising both the level of human capital formed by optimizing individuals in the home country and the average level of human capital of non-migrants in the country, can enhance welfare and nudge the economy toward the social optimum. Indeed, under a well-controlled, restrictive migration policy the welfare of all workers is higher than in the absence of this policy.
\end{abstract}

\title{
Keywords
}

Migration, human capital formation, externalities, social welfare

\section{JEL Classifications}

F22, H23, I30, J24, J61 


\section{Comments}

This is a thoroughly revised version of University of Bonn, Center for Development Research, Discussion Papers on Development Policy, Paper No. 11. We are indebted to two anonymous referees and to James Poterba for insightful comments. Partial financial support from the Humboldt Foundation is gratefully acknowledged. 


\section{Contents}

1. Introduction 1

2. Human Capital Formation in an Economy without Migration 2

3. Human Capital Formation in an Economy without Migration: The Corrective Role of Public Subsidies

4. Human Capital Formation in an Economy with Migration

5. Heterogeneous Workforce, Human Capital Formation, and Migration

6. Conclusions

Appendix I

Appendix II

References 


\section{Introduction}

There is a strong consensus that deficiency in human capital is a major reason why poor countries remain poor. Much - though not all - of the human capital in a country is a result of decisions made by individuals. But individual choices seldom add up to the social optimum. In particular, individuals do not consider the positive externalities that human capital confers in production. The result is that they acquire less human capital than is desirable. If individuals could be persuaded to form more human capital, the human capital that is acquired in an economy could rise to the socially optimal level of human capital. What makes an unfortunate state of affairs worse is that whatever quantities of human capital are formed, some - and often more than a mere some - are lost through the migration leakage. It comes as little surprise then that the concern heretofore has been to contain this leakage. In the words of a recent World Development Report: "Can something be done to stop the exodus of trained workers from poorer countries?” (World Bank, 1995, p.64). This concern follows, and is in congruence with, the large "brain drain" literature (for a systematic review see Bhagwati and Wilson, 1989).

In this paper we turn this concern on its head. We argue that the prospect of migration can well be harnessed to induce individuals to form a socially desirable level of human capital. Our key idea is that compared to a closed economy, an economy open to migration differs not only in the opportunities that workers face but also in the structure of the incentives they confront; higher prospective returns to human capital in a foreign country impinge on human capital formation decisions at home. We use a simple model in which an individual's productivity is fostered by his own human capital as well as by the economy-wide average level of human capital. We examine the relationship between the actual formation of human capital in an economy, the optimal formation of human capital in the economy, and the public provision of subsidies for the formation of human capital in the economy in the absence of migration. We calculate the (positive) level of subsidy required to ensure that the human capital formed is equal to the socially optimal human capital. We next examine the relationship between the actual formation of human capital in the economy and the optimal formation of human capital in the presence of a possibility of migration. We state conditions under which per capita output and the level of welfare of all workers are higher with migration than in its absence. We show that a controlled and restrictive migration policy can be an effective instrument to enhance welfare and nudge the economy toward the social optimum. We derive this result first when all workers are alike and are equally capable of responding to the migration prospect, and second when workers differ both in their skills and in their ability to 
respond. We conclude that migration is conducive to the formation of human capital, and that the presence of migration can substitute for the provision of public subsidies as a means of bringing about the formation of a socially preferred level of human capital. Thus, we cast migration as a harbinger of human capital gain, not as the culprit of human capital drain. An additional interesting implication of our perception of what migration can entail is that the gains from migration to the home country accrue neither from migrants' remittances nor from migrants' return home with amplified skills acquired abroad.

\section{Human Capital Formation in an Economy without Migration}

Consider a closed economy or a small open economy without migration. The economy produces a single commodity, the price of which is normalized at 1 . There are $N$ identical workers in the economy. The single production input is labor. The worker's twice-differentiable cost function of forming human capital is $c(\theta)=k \theta$, where $\theta$ is the worker's human capital (the sum total of his efficiency units of labor), and $k>0$ is a constant ${ }^{1}$. The economy-wide level of output is $Q=N f(\theta)$, where $f(\theta)=\alpha \ln (\theta+1)+\eta \ln (\bar{\theta}+1)$ is the concave, per-worker production function, $\alpha>k$ is a constant, $\bar{\theta}$ is the economy-wide average level of human capital, and $\eta>0$ represents the externalities accruing from the average level of human capital. (Externalities in production arise when as a result of individuals acquiring human capital, they not only make themselves more productive but also make each other more productive. Conversely, when individuals fail to form human capital, they not only make themselves less productive but also make each other less productive. A simple way of conditioning a worker's output not only on his own human capital but also on the human capital of others is to have the worker's output depend on the average level of human capital.) Workers supply their human capital inelastically, having acquired it instantly, though not costlessly, at the beginning of their single-period life. Workers borrow the requisite funds to support the human capital formation at a zero rate of interest.

Since labor is the only production input, the gross earnings per worker are simply equal to the output per worker, that is,

$$
f(\theta)=\alpha \ln (\theta+1)+\eta \ln (\bar{\theta}+1) \quad \text { for } \theta>0 .
$$

\footnotetext{
${ }^{1}$ A linear cost function is chosen because it simplifies the analysis. For a usage of a convex cost function see Stark, Helmenstein, and Prskawetz (1998).
} 
The coefficients $\alpha$ and $\eta$ can be interpreted, respectively, as measures of the private returns and the social returns of human capital. The worker seeks to maximize his net earnings, that is, his output minus the cost of forming human capital. The net earnings per worker function associated with human capital $\theta$ is thus

$$
W(\theta)=\alpha \ln (\theta+1)+\eta \ln (\bar{\theta}+1)-k \theta \quad \text { for } \theta>0 .
$$

The worker's decision problem is how much human capital to form. In this setting, since $\frac{\partial W(\theta)}{\partial \theta}=\frac{\alpha}{\theta+1}-k$, the worker's chosen level of human capital ${ }^{2}$ is

$$
\theta^{*}=\frac{\alpha}{k}-1>0
$$

Since there are $N$ identical workers in the economy, the average level of human capital in the economy is also $\theta^{*}$. Therefore, net earnings per worker are

$$
W\left(\theta^{*}\right)=(\alpha+\eta) \ln \frac{\alpha}{k}-\alpha+k .
$$

The following lemma will be helpful in subsequent analysis.

Lemma: For any $x>1, x \ln x>x-1 .^{3}$

By substituting $x=\frac{\alpha}{k}$ and applying the Lemma, it can be easily seen that $W\left(\theta^{*}\right)>0$. However, since the social returns of human capital are not internalized by the individual worker, $\theta^{*}$ is not the socially optimal level of human capital. Net earnings per worker are maximized when the externalities from the economy-wide average level of human capital are taken into account. To do so, we consider the function

$$
W(\theta)=\alpha \ln (\theta+1)+\eta \ln (\theta+1)-k \theta \quad \text { for } \theta>0 .
$$

The social planner's problem is to maximize the social welfare function (5) by choosing $\theta$. Since $\frac{\partial W(\theta)}{\partial \theta}=\frac{\alpha+\eta}{\theta+1}-k$, the socially optimal level of human capital is

$$
\theta^{* *}=\frac{\alpha+\eta}{k}-1
$$

\footnotetext{
${ }^{2}$ From the concavity of the $f(\theta)$ function it follows that the second-order condition for a maximum, $\frac{\partial^{2} W(\theta)}{\partial \theta^{2}}=-\frac{\alpha}{(\theta+1)^{2}}<0$, holds.

3 The proof is in Appendix I.
} 
Clearly, since $\eta>0, \theta^{* *}>\theta^{*}$. If workers choose to form this socially optimal level of human capital, net earnings per worker will become

$$
W\left(\theta^{* *}\right)=(\alpha+\eta) \ln \frac{\alpha+\eta}{k}-(\alpha+\eta)+k
$$

Since

$$
W\left(\theta^{* *}\right)-W\left(\theta^{*}\right)=(\alpha+\eta) \ln \frac{\alpha+\eta}{\alpha}-\eta=\alpha[x \ln x-(x-1)],
$$

where $x=\frac{\alpha+\eta}{\alpha}>1$, it follows from the Lemma that $W\left(\theta^{* *}\right)>W\left(\theta^{*}\right) .{ }^{4}$ Net earnings per worker attained under the social planner's choice of $\theta$ are higher than those achieved when workers choose how much human capital to form without taking into consideration the human capital externality. By construction, $W\left(\theta^{* *}\right)$ represents the highest net earnings per worker achievable, given the production technology. Unfortunately, when choosing how much human capital to form, an individual worker will not pay heed to the economy-wide average level of human capital, except as a parameter. In a large economy no individual can affect the economy's average level of human capital. Thus, the prevailing level of human capital will be $\theta^{*}$.

\section{Human Capital Formation in an Economy without Migration: The Corrective Role of Public Subsidies}

In this section we cast public subsidies as a means to correct the inefficiencies that arise from the human capital externalities. We show that a combination of subsidy and tax can achieve the social optimum.

Suppose that the cost of forming a unit of human capital is reduced by $s$ to $k$-s, and that a proportional income tax at the rate of $t$ is imposed to finance the subsidy (the subsidy bill is selffinanced by the tax revenues). The welfare of an individual is then measured by

$$
\tilde{W}(\theta)=(1-t)[\alpha \ln (\theta+1)+\eta \ln (\bar{\theta}+1)]-(k-s) \theta,
$$

and the budget constraint of the government is

$$
t[\alpha \ln (\theta+1)+\eta \ln (\bar{\theta}+1)]=s \theta .
$$

\footnotetext{
${ }^{4}$ That $W\left(\theta^{* *}\right)>W\left(\theta^{*}\right)$ also follows from the concavity of the $f(\theta)$ function since when $\theta^{* *}>\theta^{*}$, $W\left(\theta^{* *}\right)>W\left(\theta^{*}\right)$.
} 
Maximizing $\tilde{W}(\theta)$, taking $\bar{\theta}, t$, and $s$ as given, the individual will choose $\tilde{\theta}^{*}=\frac{(1-t) \alpha}{k-s}-1$. Whether or not the social optimum can be obtained under such a subsidy-tax scheme depends on whether there exist $t$ and $s$ such that $\tilde{\theta}^{*}=\theta^{* *}$ (where, to recall, $\theta^{* *}=\frac{\alpha+\eta}{k}-1$ is the socially optimal level of human capital) and the government budget constraint is satisfied. Put differently, we are looking for $t$ and $s$ such that

$$
\frac{(1-t) \alpha}{k-s}=\frac{\alpha+\eta}{k}
$$

and

$$
t(\alpha+\eta) \ln \frac{(1-t) \alpha}{k-s}=s\left[\frac{(1-t) \alpha}{k-s}-1\right] .
$$

This is a system of two equations and two unknowns, so a solution exists (see Appendix II). The subsidy $s$ and the proportional tax $t$ that emerge as a solution of this system set the welfare of the individual, $\tilde{W}\left(\tilde{\theta}^{*}\right)$ as defined in (8), equal to $W\left(\theta^{* *}\right)$ in (7).

\section{Human Capital Formation in an Economy with Migration}

In this section we cast migration policy as a tool to mitigate the inefficiency arising from human capital externalities. Assume that an opportunity to migrate to another, superior technology country, $D$, presents itself. Assume further that human capital neither depreciates nor appreciates across countries, and that the human capital of individual migrant workers is deciphered in $D$ fully and immediately upon the migrants' arrival. ${ }^{5}$ The returns to human capital in $D$ are higher than in the home country, H. A worker's output, and thus his gross earnings, in $D$ are given by $\hat{f}(\theta)=\beta \ln (\theta+1)+C$, where $\beta>\alpha+\eta$ and $C \geq 0$ are constant and exogenous to the model. ${ }^{6}$

\footnotetext{
${ }^{5}$ Chau and Stark (1999) present a modeling framework that incorporates information asymmetry: while the home country worker knows his human capital, employers in $D$ cannot discern this human capital instantaneously upon the migrant's arrival. See also Stark, Helmenstein, and Prskawetz (1997).

${ }^{6}$ Such an output function implies that the private returns of human capital in $D$ are higher than the combined private and social returns of human capital in $H$. Since the private returns of human capital are likely to be higher than the social returns $(\alpha>\eta)$ and since earnings in advanced countries are several times those in less developed countries, the assumption $\beta>\alpha+\eta$ is quite reasonable. The constant $C$ captures earnings-enhancing factors in $D$ other than a worker's own human capital, possibly human capital externalities and/or welfare benefits, and is of no material consequence. Furthermore, provided that $\beta>\alpha$, our main results carry through with some alternative specifications of the earnings function in $D$.
} 
Workers in $H$ face a probability, $p>0$, of obtaining the gross earnings $\hat{f}(\theta)$ from an employment in $D$. With probability $1-p$ they do not secure such an employment, in which case they work in $H$ for the gross earnings $f(\theta)$. The (risk neutral) worker's expected gross wage is thus

$$
F(\theta)=p[\beta \ln (\theta+1)+C]+(1-p)[\alpha \ln (\theta+1)+\eta \ln (\bar{\theta}+1)]
$$

for $\theta>0, \beta>\alpha+\eta, p>0$, and $C \geq 0$. The function of the worker's expected net earnings becomes

$$
\tilde{W}(\theta)=p[\beta \ln (\theta+1)+C]+(1-p)[\alpha \ln (\theta+1)+\eta \ln (\bar{\theta}+1)]-k \theta .
$$

Again, the worker's decision problem is how much human capital to form. Since

$$
\begin{aligned}
\frac{\partial \tilde{W}(\theta)}{\partial \theta} & =\frac{p \beta}{\theta+1}+\frac{(1-p) \alpha}{\theta+1}-k \\
& =\frac{p(\beta-\alpha)+\alpha}{\theta+1}-k,
\end{aligned}
$$

the worker's chosen level of human capital ${ }^{7}$ is

$$
\tilde{\theta}^{*}=\frac{p(\beta-\alpha)+\alpha}{k}-1 \text {. }
$$

Therefore, the level of social welfare, measured by net earnings per worker of the workers who remain in $H$, is

$$
W\left(\tilde{\theta}^{*}\right)=(\alpha+\eta) \ln \frac{p(\beta-\alpha)+\alpha}{k}-[p(\beta-\alpha)+\alpha]+k .
$$

Several results follow.

In the presence of the possibility of migration, workers choose to form more human capital than in the absence of the possibility of migration. To see this we compare $\tilde{\theta}^{*}$ in (14) with $\theta^{*}$ in (3). Since $p>0$ and $\beta>\alpha, \tilde{\theta}^{*}>\theta^{*}$. The inducement effect of migration raises the level of human capital of all workers including the workers who stay in $H$. Thus, the inadequacy of human capital formation due to the externalities is mitigated and consequently welfare can potentially be improved by the possibility of migration. ${ }^{8}$

\footnotetext{
${ }^{7}$ From the concavity of the $f(\theta)$ and $\hat{f}(\theta)$ functions it follows that the second-order condition for a maximum, $\frac{\partial^{2} \tilde{W}(\theta)}{\partial \theta^{2}}=-\frac{p(\beta-\alpha)+\alpha}{(\theta+1)^{2}}<0$, holds.

${ }^{8}$ If the inducement is strong enough, for example, if $\beta-\alpha$ is large, the home country could even be left with more total human capital in the wake of migration. The "brain gain" could then exceed the "brain drain" for the home country's total human capital.
} 
Since the private returns alone to human capital in $D$ are higher than the total returns to human capital in the home country $(\beta>\alpha+\eta)$, the net earnings of the workers who migrate to $D$ are higher than the net returns of those who stay behind. Therefore, the possibility of migration would make every home country worker better off if it makes the non-migrants better off. To examine whether the possibility of migration made the non-migrants better off we therefore compare $W\left(\tilde{\theta}^{*}\right)$ and $W\left(\theta^{*}\right)$. Viewing the probability of migration, $p$, as a policy variable, for given parameter values of $\alpha, \beta, \eta$ and $k$, the difference between $W\left(\tilde{\theta}^{*}\right)$ and $W\left(\theta^{*}\right)$ is a function, denoted as $G(\cdot)$, of $p$,

$$
G(p)=W\left(\tilde{\theta}^{*}\right)-W\left(\theta^{*}\right)=(\alpha+\eta) \ln \frac{p(\beta-\alpha)+\alpha}{\alpha}-p(\beta-\alpha) .
$$

The gains or losses from migration to a worker who remains in the home country are investigated in the following propositions.

Proposition 1: The function $G(\cdot)$ has a unique maximum at $p^{*}=\frac{\eta}{\beta-\alpha}<1$, and $G\left(p^{*}\right)>0$.

Proof: It is easy to verify that $G(p)$ is concave and hence it has a unique maximum. Since

$$
\frac{\partial G(p)}{\partial p}=\frac{\alpha+\eta}{p(\beta-\alpha)+\alpha}(\beta-\alpha)-(\beta-\alpha),
$$

the unique maximum is reached at $p^{*}=\frac{\eta}{\beta-\alpha}$. Since, by assumption, $\beta>\alpha+\eta$, we also know that $p^{*}$ is less than one and hence is a feasible probability.

Inserting $p^{*}$ into (15), we obtain

$$
G\left(p^{*}\right)=(\alpha+\eta) \ln \frac{\alpha+\eta}{\alpha}-\eta=\alpha[x \ln x-(x-1)],
$$

where $x=\frac{\alpha+\eta}{\alpha}>1$. Therefore, from the Lemma, $G\left(p^{*}\right)>0$.

Proposition 1 reveals that a carefully designed migration policy can be welfare enhancing and that the welfare gain of the non-migrants is maximized when the probability of migration is 
equal to the feasible level $p^{*}$. ${ }^{9}$ When $p=p^{*}=\frac{\eta}{\beta-\alpha}$, the human capital formed under the possibility of migration is, according to (14),

$$
\tilde{\theta}^{*}=\frac{\alpha+\eta}{k}-1=\theta^{* *} .
$$

Therefore, when the probability of migration is $p^{*}$, the level of human capital that workers choose to form is exactly the level chosen by the social planner in the absence of migration. Thus, the welfare of the workers who stay behind, as measured in (5), is inadvertently maximized by the inducement effect of the possibility of migration. It is in this sense that a migration policy can correct for the human capital externality and restore the social optimum. ${ }^{10}$

A skeptic could argue that the optimal probability $p^{*}$ is a mere theoretical concept; in practice it would be difficult, if not impossible, for the government of the home country to know the exact level of $p^{*}$. This may call into question the usefulness of migration as a tool to improve welfare and to correct for the disregard of the human capital externalities. This concern is addressed by the following proposition.

Proposition 2: $G(p)>0$ for any $0<p \leq p^{*}$.

Proof: For any $0<p \leq p^{*}=\frac{\eta}{\beta-\alpha}$, we have $\eta \geq p(\beta-\alpha)>0$. From (15),

$$
G(p) \geq[\alpha+p(\beta-\alpha)] \ln \frac{p(\beta-\alpha)+\alpha}{\alpha}-p(\beta-\alpha)=\alpha[x \ln x-(x-1)],
$$

where $x=\frac{p(\beta-\alpha)+\alpha}{\alpha}>1$. Thus, from the Lemma, $G(p)>0$.

\footnotetext{
${ }^{9}$ This result is more general than our specific functional forms suggest. As long as the welfare function is singlepeaked, $\theta$ is positively related to $p$, and $\theta^{* *}$ is attainable for some (interior) $p$, the result will hold. In other words, when the possibility of migration induces sufficiently strong incentives to form human capital, there exists a level of the probability of migration such that the single peak of the welfare function is reached. However, if welfare were to be measured by the ex ante expected net earnings in (13), the peak of the welfare function cannot be reached at an interior probability of migration. We find this case, which calls for setting the probability of migration equal to one, both uninteresting and impractical.

${ }^{10}$ If the problem of the social planner in the presence of the possibility of migration is perceived as maximizing the $e x$ ante expected net earnings in (13), then the socially optimal level of human capital will be higher than its equivalent in the absence of the possibility of migration $\left(\theta^{* * *}\right)$. In such a case, the inducement effect of migration cannot bring the formation of human capital to its socially optimal level. However, it seems more appropriate to define the social optimum ex post, that is, from the perspective of the non-migrants.
} 
Proposition 2 states that, as long as the probability of migration is not greater than $p^{*}$, the net earnings of a worker who stays in $H$ under migration are higher than the net earnings per worker without migration. This suggests the practical use of migration as a welfare-enhancing policy tool even when the government of $H$ does not know the exact level of the optimal probability. Viewed in this light, a tightly controlled migration policy is not necessarily a bad policy. It is not unusual for governments of developing countries to impose restrictions on migration. In China, for example, not all those who can safely expect to have higher earnings abroad (for instance, because foreign organizations are perfectly willing to employ them) can leave. Because the government does not grant emigration visas or passports liberally, the Chinese authorities have been criticized for restricting migration. Yet, the restrictive migration policy may rest on a sound economic rationale. A government of a developing country that controls $p,{ }^{11}$ without knowing $p^{*}$, can adopt a cautious migration policy as an effective tool to nudge the human capital level toward its social optimum.

Since $p^{*}=\frac{\eta}{\beta-\alpha}$, the optimal probability decreases as the gap between the marginal productivities of a $D$ country worker and an $H$ country worker widens. Our analysis implies that poorer countries need to impose stricter migration restrictions to improve welfare. As a country develops, migration restrictions can be relaxed and still be welfare enhancing.

Notice that $\lim _{p \rightarrow 1} G(p)=(\alpha+\eta) \ln \frac{\beta}{\alpha}-(\beta-\alpha)$. Since $\lim _{p \rightarrow 1} G(p)<0$ for a large enough $\beta$, we obtain the following proposition, which further supports the use of a restrictive migration policy.

Proposition 3: When $\beta$ is large enough, too liberal a policy of migration can reduce the welfare of the workers who stay in the home country.

Proof: $\lim _{p \rightarrow 1} G(p)<0$ for a large enough $\beta$. Since $G\left(p^{*}\right)>0$ and $G^{\prime}(p)<0$ for $p^{*}<p<1$, there exists $\bar{p}$ such that $G(p)<0$ for all $p>\bar{p}$. (Furthermore, such $\bar{p}$ is lower the higher the difference between $\beta$ and $\alpha$.)

To sum up, our analysis suggests that a controlled and restrictive migration policy can be welfare enhancing for non-migrants. In particular, in the presence of a controlled migration policy

\footnotetext{
${ }^{11}$ We assume that although the government of $H$ cannot force individuals to form more human capital than they freely choose to form, it can exercise control over their exits to the foreign country.
} 
with the probability of migration set at $p^{*}$, the level of human capital that the workers are induced to form turns out to be the socially optimal level of human capital had the workers not migrated. Technically, our analysis suggests that there is a cutoff probability, $\bar{p}$, below which migration benefits the non-migrants and above which migration hurts the non-migrants.

Illustrative numerical examples may be useful. Suppose that the social returns of human capital in $H$ are 20 percent of the private returns, that is, $\eta=0.2 \alpha$, and that human capital is 10 times more productive in $D$ than in $H$, that is, $\beta-\alpha=10 \alpha$. Then $p^{*}=0.02$ and $\bar{p}=0.0425 .{ }^{12}$ When $\eta=0.2 \alpha$, the level of $\beta$ that makes $\lim _{p \rightarrow 1} G(p)<0$ is only 1.4 times of the size of $\alpha$. This is far from being unusually high.

\section{Heterogeneous Workforce, Human Capital Formation, and Migration}

The intersection of migration with the presence of externalities gives rise to a concern that those who leave adversely affect the productivity of those who stay behind. If the human capital of the workers who migrate is higher than the human capital of the workers who stay behind, and if a worker's output is rising in the average level of human capital, the non-migrants will end up worse off; the workers who migrate impose a negative externality on the workers who remain. To address this concern, we examine what might be expected to constitute the worst possible case from the perspective of the low skill workers - the case in which these workers cannot participate in migration at all. We show that even in such a harsh environment, the human capital formation response of the high skill workers to the migration prospect can lead to the low skill workers being better off despite the migration of some of the high skill workers.

Let us now relax the assumption that the workforce is homogeneous. Suppose that there are two types of workers in $H$ : Low-ability, type-1 workers and high-ability, type-2 workers. Human capital formation is costlier for type- 1 workers. Let the cost of forming human capital by a type-1 worker be $C(\theta)=k_{1} \theta$, where $k_{1}>0$ for $\theta \leq \underline{\theta}$ and $+\infty$ otherwise. Let the cost of forming human capital by a type- 2 worker be $C(\theta)=k_{2} \theta$, where $0<k_{2}<k_{1}$. Let the probability of being selected

\footnotetext{
${ }^{12}$ With the parameter values specified in this example, it follows from (15) that $G(p)=[1.2 \ln (10 p+1)-10 p] \alpha$. It is easy to verify that $G(p)$ is strictly concave with a unique maximum at $p^{*}=0.02$ and that, for $0<p<1, G(p)=0$ has a unique solution at $\bar{p}=0.0425$. Thus, in this example, $G(p)>0$ for $0<p<0.0425$ and $G(p)<0$ for $0.0425<p<1$.
} 
into employment in $D$ for an $H$ country worker whose human capital is $\theta$ be $p$ if $\theta>\underline{\theta}$, and 0 otherwise. Workers in $H$ face the same net earnings function as in (2). We consider the case where $\alpha$ is sufficiently large, such that in the absence of migration the optimal level of human capital formed by type- 1 workers is $\theta_{1}^{*}=\underline{\theta}$, and the optimal level of human capital formed by type- 2 workers is $\theta_{2}^{*}=\frac{\alpha}{k_{2}}-1>\underline{\theta}$. Figure 1 portrays this configuration of outcomes. Thus, in the absence of migration, the average level of human capital in $H$ is $\bar{\theta}=\frac{N_{1} \underline{\theta}+N_{2} \theta_{2}^{*}}{N_{1}+N_{2}}$, where $N_{1}$ and $N_{2}$ are the numbers of type-1 and type-2 workers, respectively.

The presence of an opportunity to migrate and earn higher wages of $\beta \ln (\theta+1)+C$ induces the type- 2 workers to form more human capital. However, the type- 1 workers are immune to this inducement effect because of their inability to form more human capital than the minimal level required for the probable employment in $D$. Therefore, under the possibility of migration, the levels of human capital formed by type-1 and type- 2 workers are, respectively, $\tilde{\theta}_{1}^{*}=\underline{\theta}$, and $\tilde{\theta}_{2}^{*}=\frac{p(\beta-\alpha)+\alpha}{k_{2}}-1$, from (14), and hence, the average level of human capital of the workers who remain in $H$ is $\bar{\theta}_{m}=\frac{N_{1} \underline{\theta}+(1-p) N_{2} \tilde{\theta}_{2}^{*}}{N_{1}+(1-p) N_{2}}$.

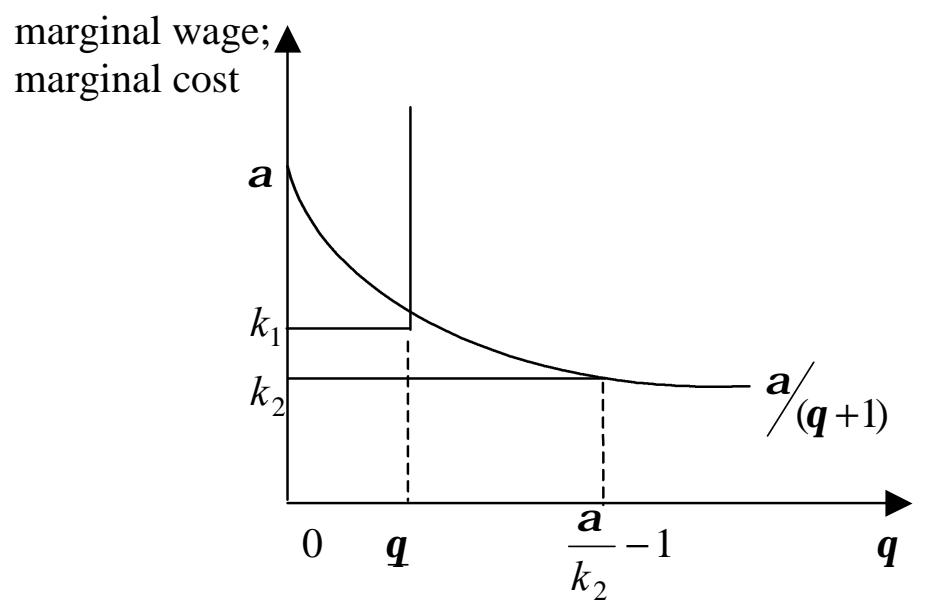

Figure 1 
A comparison between $\bar{\theta}_{m}$ and $\bar{\theta}$ reveals that a sufficient condition for $\bar{\theta}_{m}>\bar{\theta}$ to hold is $(1-p) \tilde{\theta}_{2}^{*}>\theta_{2}^{*}$, which in turn is true if $(1-p)\left(\tilde{\theta}_{2}^{*}+1\right)>\theta_{2}^{*}+1$. Since

$$
\frac{(1-p)\left(\tilde{\theta}_{2}^{*}+1\right)}{\theta_{2}^{*}+1}=\frac{p(1-p)(\beta-\alpha)+(1-p) \alpha}{\alpha}=1+\frac{p[(1-p)(\beta-\alpha)-\alpha]}{\alpha},
$$

$(1-p)\left(\tilde{\theta}_{2}^{*}+1\right)>\theta_{2}^{*}+1$ holds if $p>0$ and $(1-p)(\beta-\alpha)-\alpha>0$, or, if $0<p<\frac{\beta-2 \alpha}{\beta-\alpha}$.

Therefore, assuming $\beta>2 \alpha$, the average level of human capital of the non-migrants in the wake of migration is higher than that in the absence of migration as long as $0<p<\frac{\beta-2 \alpha}{\beta-\alpha}$. In terms of our numerical example $\beta-\alpha=10 \alpha$, this implies that migration raises the average level of human capital in $H$ as long as the probability of migration by type-2 workers is less than 90 percent, which is hardly a restriction. Thus, the possibility of migration is most likely to bring about a "brain gain," on average.

When the migration prospect leads to a higher average human capital, type-1 workers are obviously better off, benefiting from a greater human capital externality. Whether the remaining type- 2 workers are also better off under migration is less clear. The change of welfare of a type-2 worker who remains in $H$ is

$$
G_{2}(p)=W\left(\tilde{\theta}_{2}^{*}\right)-W\left(\theta_{2}^{*}\right)=\alpha \ln \frac{p(\beta-\alpha)+\alpha}{\alpha}+\eta \ln \frac{\bar{\theta}_{m}+1}{\bar{\theta}+1}-p(\beta-\alpha) .
$$

Since $\frac{\partial \bar{\theta}_{m}}{\partial p}=\frac{\left[N_{1} \underline{\theta}+(1-p) N_{2} \tilde{\theta}_{2}^{*}\right] N_{2}}{\left[N_{1}+(1-p) N_{2}\right]^{2}}+\frac{(1-p) N_{2}(\beta-\alpha) / k_{2}-N_{2} \tilde{\theta}_{2}^{*}}{N_{1}+(1-p) N_{2}}$, we have

$$
\left.\frac{\partial \bar{\theta}_{m}}{\partial p}\right|_{p=0}=\frac{\left(N_{1} \underline{\theta}+N_{2} \theta_{2}^{*}\right) N_{2}}{\left(N_{1}+N_{2}\right)^{2}}+\frac{N_{2}(\beta-2 \alpha) / k_{2}+N_{2}}{N_{1}+N_{2}}>0
$$

where the inequality follows from the assumption that $\beta>2 \alpha$. Drawing on this inequality, we next differentiate (16) with respect to $p$ and evaluate the result at $p=0$ to obtain that $\left.\frac{\partial G_{2}(p)}{\partial p}\right|_{p=0}>0$. By continuity, $G_{2}(p)>0$ holds for $p$ in a small neighborhood of zero. This suggests that the type- 2 workers who remain in $H$ are indeed also better off when the probability of migration is small enough. 
The discussion in this section reaffirms the main result of the previous section: a restrictive migration policy can stimulate human capital formation and improve the welfare of all workers. In addition, the possibility of a "brain drain" of high-ability workers from $H$ can confer a positive externality on low-ability workers in $H$. While the potential prevalence of a positive externality from migrants to non-migrants has already been recognized (Stark, 1995), the source of the externality identified here is new.

Two qualifications are in order. Suppose that instead of linking the productivity of workers of different types by the average level of human capital we were to link their productivity by direct complementarity. In such a case, the migration of high-ability, type-2 workers might lower the productivity of low-ability, type-1 workers by virtue of having fewer high-ability workers in $H$. The possibility that migration by high-ability workers may impinge adversely on the welfare of lowability workers because of a progressive tax structure needs be mentioned as well. An adverse repercussion could arise if high-ability workers are taxed at relatively high rates to finance public goods and transfer payments that benefit low-ability workers. In a model that incorporates these considerations, the welfare calculus resulting from the possibility of migration by high-ability workers will be more intricate than the one conducted in the present paper.

\section{Conclusions}

When the productivity of an individual in a closed economy or in a small open economy without migration is fostered not only by his own human capital but also by the average level of human capital, the individual who optimally chooses how much to invest in costly human capital formation will, from a social point of view, under-invest. Consequently, social welfare is affected adversely. Not surprisingly, a combination of subsidies and taxes can correct the inefficiencies that arise from the human capital externalities. Somewhat surprisingly, migration too can mitigate the undesirable outcome. In fact, a well-specified migration policy can ameliorate the tendency to under-invest in human capital and instead permit formation of a socially desirable level of human capital. The favorable effect of migration and the associated welfare gain apply not only when all individuals can respond to the migration prospect but also when only a subset of individuals are affected. In the latter case, even those who cannot gain from migration by participating in it stand to gain from the response of others to the migration prospect. 
The propensity to acquire skills is not invariant to the possibility of having the skills rewarded highly. This consideration appears to have escaped attention by migration scholars for many years. The pioneering work of Grubel and Scott (1966) provides a careful account of why a country need not "lose by the emigration of highly skilled individuals." In Grubel's and Scott's words " $[E]$ migration should be welcomed whenever two conditions are met. These are, first, that the emigrant improves his own income and, second, that the migrant's departure does not reduce the income of those remaining behind" (p. 270). That the prospect of migration modifies the human capital formation calculus, thereby entailing a welfare gain for the non-migrants (rather than being inconsistent with a welfare loss) has neither been mentioned by Grubel and Scott, nor by those who followed in their steps. This paper draws attention to this possible relationship. We have shown that the behavioral response to the prospect of migration nourishes both a "brain drain" and a "brain gain", and that a skillfully executed migration policy can confine and utilize the response to secure a welfare gain for all workers.

In our model, the social welfare of workers is enhanced as long as the probability of migration is kept below a critical level. The magnitude of this critical level of the migration probability, which is the optimal probability that maximizes the welfare gain from migration, decreases with the productivity differential of human capital between the destination country and the home country. These results offer a positive policy implication: a poor country should adopt a restrictive migration policy and gradually relax the restriction as its economy develops. When the workforce is heterogeneous, a carefully designed migration policy can benefit both high-skill and low-skill workers, even when the low-skill workers cannot directly exploit the migration prospect. Furthermore, the larger the wage differential between the destination country and the home country, the greater the incentive to accumulate human capital and the more likely that the "brain drain" of migrants will be outweighed by the "brain gain" of non-migrants. It follows then that, contrary to the received wisdom, the poor in a poor country stand to gain more and need to fear less from properly controlled migration by skilled members of the country's workforce.

Presenting migration as a device that facilitates the formation of a socially desirable level of human capital need not imply that migration is the only - or even the preferred - means of achieving this objective. Implementing a program to mandate the acquisition of compulsory skills is another way to facilitate the formation of a socially desirable level of human capital, as is an offering of generous (probabilistic) prizes to those who achieve this goal. Whereas recourse to these schemes entails a cost to the government, however, migration requires none. 
We have assumed that the human capital formed in the home country is perfectly transferable to the destination country. In the preceding section we have assumed that the probability of migration depends on the workers' level of skill. This latter assumption can duly salvage the human capital formation incentives associated with the prospect of migration when the human capital formed in the home country is not on a par with the comparable human capital formed in the destination country. Specifically, and even when the returns to human capital in the home country are low, our key argument is retained upon letting the probability of migration depend positively on the attainment of the necessary skills.

Our model stands in sharp contrast to the received literature on the brain drain. In particular, we consider the policy implications for a government that can costlessly exercise control over the migration of skilled workers: while the prescription of the standard approach does not favor migration, ours allows it, though with caution. Implicitly, however, our model shares a concern with that literature. We have assigned a well-defined role and a specific policy mandate to the government of the home country, which presupposes the existence of effective political institutions. Weaknesses and shortcomings in this regard could hinder the feasibility of the action we advocate.

Finally, we note that our key "inducement effect" of migration is quite robust to alternative functional and model specifications. In the present paper, the analysis has been based on a simple model with simple cost and benefit functions. These have fostered considerable transparency and straightforward tractability. In a related paper (Stark, Helmenstein, and Prskawetz, 1998), intertemporal utility-maximizing individuals who choose the level of their human capital optimally respond to the possibility of migration in a manner akin to that of workers in the simple specification employed in the present paper. 


\section{Appendix I}

Proof of Lemma: We seek to show that for any $x>1, x \ln x>x-1$. Since

$$
\begin{aligned}
& \lim _{x \rightarrow 1} x \ln x=\lim _{x \rightarrow 1} x-1=0 ; \\
& \frac{\partial(x \ln x)}{\partial x}=1+\ln x>\frac{\partial(x-1)}{\partial x}=1 ; \\
& \frac{\partial^{2}(x \ln x)}{\partial x^{2}}=\frac{1}{x}>0 ; \text { and } \frac{\partial^{2}(x-1)}{\partial x^{2}}=0,
\end{aligned}
$$

we have

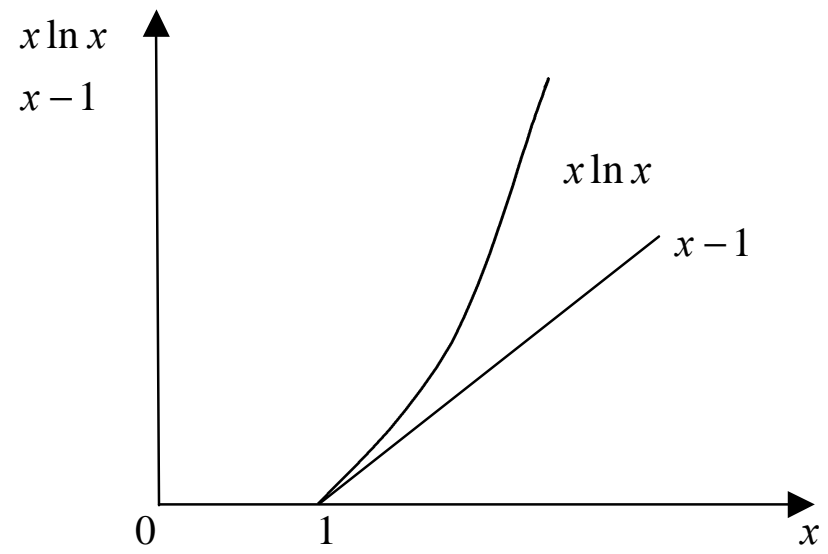




\section{Appendix II}

Let $\frac{\alpha+\eta}{k}=x$. Then from (10): $\frac{(1-t) \alpha}{k-s}=x$, or

$$
(1-t) \alpha=x(k-s)
$$

Let us rewrite (11) using $x$ and (A1) as

$$
t k x \ln x=s(x-1)
$$

or

$$
s=\frac{t k x \ln x}{x-1} .
$$

Inserting this into (A1) gives

$$
(1-t) \alpha=x\left[k-\frac{t k x \ln x}{x-1}\right]
$$

or

$$
t=\frac{\alpha-k x}{\alpha-\frac{k x^{2} \ln x}{x-1}} .
$$

Let $\delta=\frac{x-1}{x \ln x}$, where $0<\delta<1$ as follows from the Lemma. Then,

$$
t=\frac{\alpha-k x}{\alpha-\frac{k x}{\delta}} .
$$

Since $\alpha-\frac{k x}{\delta}=\alpha-\frac{k}{\delta} \cdot \frac{\alpha+\eta}{k}=\frac{\alpha(\delta-1)-\eta}{\delta}$ and $\alpha-k x=\alpha-k \frac{\alpha+\eta}{k}=-\eta$, we can rewrite (A3) as

$$
t=\frac{-\eta}{\frac{\alpha(\delta-1)-\eta}{\delta}}=\frac{\delta \eta}{(1-\delta) \alpha+\eta} .
$$

Since $0<\delta<1$, it is clear from (A4) that $0<t<1$. Inserting this $t$ in (A2) gives

$$
s=\frac{\delta \eta}{(1-\delta) \alpha+\eta} \cdot \frac{k}{\delta}=\frac{\eta}{\eta+(1-\delta) \alpha} \mathrm{k}<\mathrm{k} .
$$

Now, with $t=\frac{\delta \eta}{(1-\delta) \alpha+\eta}$ and $s=\frac{k \eta}{\eta+(1-\delta) \alpha}$ we have

$\tilde{W}\left(\tilde{\theta}^{*}\right)=(\alpha+\eta) \ln \left(\tilde{\theta}^{*}+1\right)-k \tilde{\theta}^{*}-t(\alpha+\eta) \ln \left(\tilde{\theta}^{*}+1\right)+s \tilde{\theta}^{*}=(\alpha+\eta) \ln \left(\theta^{* *}+1\right)-k \theta^{* *}=W\left(\theta^{* *}\right)$. 


\section{References}

Bhagwati, J., Wilson, J.D., 1989. Income Taxation and International Mobility, MIT Press, Cambridge, MA.

Chau, N.H., Stark, O., 1999. Human capital formation, asymmetric information, and the dynamics of international migration. In: Razin, A., Sadka, E. (Eds.), The Economics of Globalization: Policy Perspectives from Public Economics. Cambridge University Press, Cambridge.

Grubel, H.B., Scott, A.D., 1966. The international flow of human capital. American Economic Review 56, 268-274.

Stark, O., 1995. Return and dynamics: the path of labor migration when workers differ in their skills and information is asymmetric. Scandinavian Journal of Economics 97, 55-71.

Stark, O., Helmenstein, C., Prskawetz, A., 1997. A brain gain with a brain drain. Economics Letters 55, 227-234.

1998. Human capital depletion, human capital formation, and migration:

a blessing in a "curse"?. Economics Letters 60, 363-367.

World Bank, 1995. World Development Report 1995, Oxford University Press, New York. 
Authors: Oded Stark, Yong Wang

Title: Inducing Human Capital Formation: Migration as a Substitute for Subsidies

Reihe Ökonomie / Economics Series 100

Editor: Robert M. Kunst (Econometrics)

Associate Editors: Walter Fisher (Macroeconomics), Klaus Ritzberger (Microeconomics)

ISSN: $1605-7996$

(c) 2001 by the Department of Economics and Finance, Institute for Advanced Studies (IHS),

Stumpergasse 56, A-1060 Vienna • F 
ISSN: 1605-7996 